\title{
Public Financial Support for the Development of Cultural Industry in Shanghai
}

\author{
Jingjing $\mathrm{Wu}^{1}$ \\ ${ }^{1}$ School of Management, Shanghai University of Engineering Science, Shanghai, China \\ Correspondence: Jingjing Wu, School of Management, Shanghai University of Engineering Science, Shanghai, \\ No.333, Longteng Road, Songjiang District, Shanghai, China. Tel: 86-150-0017-1883. E-mail: jing.jingw@163.com
}

Received: April 29, 2014 Accepted: May 15, 2014 Online Published: June 12, 2014

doi:10.5430/wjss.v1n2p60 URL: http://dx.doi.org/10.5430/wjss.v1n2p60

\begin{abstract}
As we all know, cultural products belong to quasi-public goods, with a typical externality. Therefore, only relying on market forces to develop the cultural industry is not enough. Cultural industry needs the government to provide strong support and guidance. Shanghai as China's most economically developed regions, although its cultural industry has made some progress in recent years, the situation of development is just passable. In the long term, the development potential of cultural industry is needed to be deeply digged. This paper from the background of the development of cultural industry in Shanghai, analyzes the real problems existing in the development of cultural industry in Shanghai to further explore how public finances to better promote the development of cultural industry, to provide the impetus for the positive and healthy development of Shanghai's cultural industry, in order to promote the pace of economic ahead.
\end{abstract}

Keywords: cultural industry, cultural products, public finance, taxation

\section{The Research Status}

It is considered that the cultural products have ideological attributes and features, which need the government to take some measures to guide the value of them (Han Hui \& Wu Jiang 2009). In addition, they thought that the externality of the cultural products determined that the cultural products must be provided by the government. It is considered that thought and concept lagging behind, the cultural market mechanism being not perfect, the cultural industry lacking of talent and the cultural industry developing not balanced are major problems of the local cultural industry (Wu Xueli \& Li Xuijin 2010). Kuang Daoqiu (2012) thought that the proportion of expenditure of cultural construction which is supported by public financial is inadequate and inefficient. There are not enough ways of financing. What's more, the success rate of financing is quite low. At last, the environment and mechanisms of financing need to be improved. Du Xiaowei (2013) considered cultural products have positive externality and the attributes of public goods. If we have a large financial support for cultural industry, to a certain extent, it can offset the positive externalities and the influence which is due to the public goods attributes, and increase the supply of cultural products. Ye Juhua (2013) considered that to promote the development of cultural industry, the government should increase the investment of non-profit cultural industry and give more tax incentives to the profit cultural industry.

\section{The Current Background of Development of the Cultural Industry in Shanghai}

Throughout the world today, the more economically developed the regions are, the greater proportion of their tertiary industry accounted for the national economy.In addition, the speed of the development of cultural industry in the tertiary industry was more rapid. It is not exaggerated to say that all of the countries will focus on the development of the cultural industry in the future. The huge roles in promoting the cultural industry to the economy not only reflect in that it can promote the development of the industry itself, but also can promote the development of other industries day by day. Moreover, the benefits arising from such promotion is quite immeasurable. The cultural industry is a sunrise industry with great potential and broad prospects. Although Shanghai is our country's most 
economically developed region, but the development of its cultural industries in some ways still not as good as some other cities or provinces in our China. Therefore, developing Shanghai's cultural industry has a crucial significance.

Chinese culture has a long history and is profound. Our excellent Chinese culture can clean the people's mind, edify people's sentiments and inspire people's inspiration. Cultural products derived from the Chinese culture can play the same role. It can provide a steady stream of intellectual impetus for the development of social production. The culture of Shanghai was based on the Chinese traditional culture and integrated into the western culture.In this kind of environment, it gave birth to the Shanghai-style culture with local characteristics. If we take advantage of the Shanghai-style culture properly, develop the cultural industry with Shanghai characteristics, we are sure to make it become the new growth of future economic and social development of Shanghai.

As China's largest city, Shanghai is also the birthplace of China's modern cultural industry. Early in the last century, newspapers, movies and many other cultural industries as a typical representative booming in Shanghai. And over a period of time, they were very glorious, which had laid a solid historical foundation for the development of Shanghai cultural industry. Thus, the development of Shanghai's cultural industry itself has already had a good historical and cultural environment. Cultural industry itself is not only an industry with great prospects for the economy, but also in line with our China's goals which are taking the road of sustainable economic development and realizing the dream of building a harmonious, resource-saving and environmental friendly society. Shanghai is in the period of economic development and transformation and adhere to the mainline of focusing on innovation-driven restructuring and development. So in the process of development of cultural industry, the government will attaches great importance to developing this industry, makes some advice for it, and also provides some political protection for the development of cultural industry. On the one hand, as a modern metropolis, the ability to accept new things of people in Shanghai constantly strengthened. On the other hand, people's material life has also been fully met, their concept of life is also undergoing profound changes, so they are more inclined to pursue spiritual life enriched. The consumption of cultural products can meet the people's needs about the spiritual life. For example, more and more people will go into the cinema now. Chinese film industry has been the rapid development in recent years and refreshed the annual box office records again and again, even up to several hundred million, which made a great contribution to the economic development. Such situation will undoubtedly have a huge impact on the other cultural goods of manufacture and creation, which can stimulate the production of cultural goods and the creators' infinite power and enthusiasm. In addition, Shanghai has a unique location. Shanghai is in the eastern coastal regions - the Yangtze River Delta, where the domestic and international talent gathered. So it is conducive to the development of cultural industry such as knowledge-intensive industry. Based on the local environment, we still need to absorb more excellent creative from foreign culture and learn some advanced foreign experience. Meanwhile, the development of economic can provide strong financial support for the development of cultural industry. So a place like Shanghai can provide experience, intellectual and funding support for the development of cultural industry.

In summary, Shanghai has already had all kinds of good conditions to prosper the Shanghai-style culture and develop the cultural industry. The priority now is how to use the power of public finances to solve the problems appeared in the development of Shanghai culture industry.

\section{The Main Problem of the Development of Cultural Industry in Shanghai}

Despite these favorable background conditions, despite the cultural and creative industry such as animation industry in a good momentum of development in these years and other industries are entering into the development on track as if wakening from a dream. But in the second decade of the twenty-first century, facing the situation of deepening economic reform, the development of Shanghai's cultural industry is still not satisfactory. In addition, it faces enormous resistance. Even if more and more people in Shanghai began to change consumer attitudes and pay more attention to the pursuit of cultural products, and more and more enterprises start into the ranks of the cultural industry, which makes cultural products market have been appeared a prosperity tendency.But the reality is still not optimistic.There are still several quite serious aspects, namely as follows:

\subsection{The Local People in Shanghai Lack a Strong Sense of Belonging to the Local Culture}

In Shanghai, people's cultural consumption ais more biased on the cultural products from abroad, while do not buy the cultural goods produced in the local place. For example, in the film market, people are fond of foreign films, which are often the upper hand in the competition with the domestic film. For example, a film called "Titanic" which was packaged into 3D, earned more than a billion yuan in Chinese film market. Especially in Shanghai, it launched a strong viewing wave. We can not deny that this is a famous classic movie. But if the change of movie produced 
domestically is done by ourselves, it may not have such good results. Moreover, in recent years, Shanghai's film industry has been a recession trend which lacks of stamina in the cultural market. There are few masterpieces in the cultural industry, it become a drag during the development process. It no longer has the glorious place like the past. We have to say that this is, as the birthplace of Chinese cinema career, Shanghai's sadness.

\subsection{Externalities Lead to Insufficient Cultural Innovation, the Overall Quality of Cultural Products not High, the Speed and Scale of the Development of Cultural Industry not Given a Qualitative Change}

On the one hand, the producers and the creators who are engaged in cultural industry due to the reason of spillover, they lack the enthusiasm and initiative of cultural innovation. It results in the situation that the cultural industry is lack of creation, the overall quality of cultural products can not be improved, even it appears the convergence of cultural products phenomenon. The culture industry lacking innovation has always been a problem which has existed for a long time. This is one of the main reasons for the slow development of this industry. On the other hand, precisely because of the externality of cultural products existed, under the socialist market economy, only relying on the forces of market to promote the prosperity of the cultural industry has no reality. Nature itself has the feature of quasi-public cultural products, which will limit the scale of its development. Due to the revenues of quasi-public goods are minimal, many companies are reluctant to invest in this area. At last, the cultural industry has always been in a limited scale. It can only develop in the inner circle. Therefore, this reason restricts the prosperity of the cultural industry.

\subsection{Many Cultural Products Lack the Profound Meaning, and don't Have a Distinctive Specialties of Shanghai}

Culture should have a specific social nature and the connotation of ethnic consciousness, which is inseparable from the particular mental and spiritual civilization to shape in the environment of the city. In order to achieve the profound meaning in the Shanghai's cultural goods, we must rely on the power of cultural innovation, and base on the specific, having reginal style of the traditional Shanghai culture. If we do like this, we can introduce new features to create and enrich the cultural products of Shanghai. The cultural products operated by the Shanghai cultural industry, breaking away from the local culture of Shanghai, so that it seems to have no local features. It is just a relatively simple pursuit of the rich species, the mighty, the advanced technology and the excellent benefits, while ignoring its inherent nature. The result is poor content, which causes the prosperity of the cultural industry just being a symptom. If there is no deep meaning and not having the feature of Shanghai, our consumers will not pay the bill. If the cultural connotation don't really play the role of improving the quality of urban civilization and cultural product, and thus it may not promote cultural industry to move in the right direction.

3.4 The Vulgar Culture which Goes against to the Moral Bottom Line and the Phenomenon of Cultural Infringement Are Full in the Market

Unscrupulous traders tend to reap profits from the market, although people will be severely condemned the phenomenon of these violations of law, they are unable to really change this situation. They can only let their like parasites and drugs go on to corrode the people's minds and hinder the healthy development of the cultural market. Modern Shanghai people's sense of ownership and the consciousness of rights safeguarding continue to strengthen, they will use the network medias to give the behavior of spreading vulgar culture severe or even fatal blow, but few people are able to take effective measures to remove out the source of the trouble like these violations. Ultimately it will be making a comeback after the limelight, and there will be the momentum of "wild fire, in spring". So the cultural market are still not well developed. The behavior of culture infringement is not uncommon, although the measures of punishment come out one after the other, they are eventually palliatives. Lacking the truly effective means to cure these illegal acts, it results in the development of cultural industries which is always existing such a tumor.

\subsection{Part of the Cultural Industry Is Shrinking}

The unbalance situation of the development of the cultural industry has become more and more serious. On the one hand, part of the cultural and creative industry, as the representers like animation, visual arts, are flourishing in a proud attitude. On the other hand, part of the development of traditional cultural industry, as the representers shown in the chart 3.5.1, like mass culture and libraries, are limping. This situation is showing a serious polarization between these two aspects. The amount of musical groups, drama groups and other organizations and practitioners is in this drastic reduction in the past two years. According to statistics from the chart3.5.2, the number of song and dance troupe, light music troupes of the institutions and personal in 2011 was respective 23 and 506, while in 2010 the number was retained 60 and 1394, which showed that the number of retained in 2011 was even not to half of the number in 2010. In addition, libraries and the organization of the mass cultural institutions also evidently started to 
be in the decline with a slowly speed in 2012, while the rest of the industry also had more or less decreased. Indeed, many nonprofit cultural enterprises and institutions because of their non-profit, causes the result of lacking adequate financial support. What's more, the market cannot be fully provided funds to help its development, so they are facing difficulty that is gradually disappearing.

Table 1. Quantity of employees in major cultural institutions in main years

\begin{tabular}{lrll}
\hline Category of institution & 2010 & 2011 & 2012 \\
\hline Art & 9482 & 10467 & 11368 \\
Libraries & 2180 & 2264 & 2089 \\
Archives Institution & 3822 & 3765 & 4125 \\
Mass Culture & 4702 & 4856 & 4775 \\
History Relic & 2558 & 2736 & 3292 \\
$\begin{array}{l}\text { Cultural and } \\
\text { Institutions }\end{array}$ & 61966 & 67616 \\
$\begin{array}{l}\text { Institutions Engaged in News } \\
\text { Publishing }\end{array}$ & & & \\
Other Cultural Institutions & 60358 & 199890 & 202037 \\
Total & 5545 & 7685 & 3774 \\
\hline
\end{tabular}

Description: the source is from Shanghai statistical yearbook

Table 2. Art institutions and personnel

\begin{tabular}{lllll}
\hline \multirow{2}{*}{ Item } & 2010 & & 2011 & \\
& $\begin{array}{l}\text { institutions } \\
\text { unit }\end{array}$ & $\begin{array}{l}\text { personal } \\
\text { person }\end{array}$ & $\begin{array}{l}\text { institutions } \\
\text { unit }\end{array}$ & $\begin{array}{l}\text { personal } \\
\text { person }\end{array}$ \\
\hline Total & 617 & 12986 & 195 & 6257 \\
Art Performance Troupes & 201 & 7095 & 114 & 5002 \\
Drama, Children's Play and Comedy Troupes & 1 & 115 & 1 & 118 \\
Opera,Ballet and Dance Troupes & 20 & 833 & 10 & 628 \\
Song and Dance Troupe, Light Music Troupes & 60 & 1394 & 23 & 506 \\
Orchestra, Chorus & - & - & 3 & 60 \\
Cultural and Performance Troupes and Ulanmuchi & 8 & 240 & 6 & 176 \\
Local Opera Troupes & 67 & 3134 & 66 & 3042 \\
Recitation and Ballad Troupes, Acrobatics & 4 & 338 & 2 & 257 \\
Comprehensive performing arts groups & - & - & 3 & 215 \\
Art Performance Places(Theaters and Music Halls) & 63 & 1065 & 66 & 1162 \\
Art Creation Institutions & 17 & 97 & 15 & 93 \\
Art Exhibition Institutions & 3 & 25 & - & - \\
Others & 333 & 4704 & - & - \\
\hline
\end{tabular}

Description: the source is from Shanghai statistical yearbook

3.6 In the Early Period of Start-up, There Are a lot of Phenomena of Inputs and Outputs Being Unbalanced which Bring about Small and Medium Cultural Enterprises no Longer Pperating, even Facing the Risk of Collapse

The inputs and outputs of the cultural industry have great uncertainty, and it is not able to get a relatively considerable economic profit in a short time. Small and medium cultural enterprises in the early days need more funds to invest, particularly the research and development funding. In Shanghai, with the competition inside the industry becoming fiercer and fiercer, many SMEs in itself do not have very strong financial strength. When it faces a funding strand breaking, and have not enough cash to meet the needs, if they cannot take back the early investment, 
it is likely to face a crisis of bankruptcy, losing the opportunities of development. While to the market, flexible SMEs have strong creativity in many situations, if they were missing, some of the big companies can easily become too complacent, not seeking to break in the long run. So the industry will not make the big progress. In addition, if the SMEs fail, it will also affect other companies' initiative wishing to enter the industry. At last, the scale of the industry lacks the timely supplement. As a result, it may lead large companies to monopolize the market so that they will undermine the fair competition of the industry norms, and ultimately affect the development of cultural industry.

It is because of the combined reasons above, making the development of cultural industry in Shanghai confined into the ivory tower in the world.It does not have a competitive advantage in the world or even in domestic, not to mention to be eye-catching, so its road of development is quite bumpy.

\section{The Measures Better to Promote the Development of Cultural Industries of Public Finances in Shanghai}

The questions we meet are quite serious. The specificity of cultural products makes it powerless to rely on the free development of the market. It must rely on the governments' forces and depend on the strength of public finances. The development of cultural industry need right medicine with comprehensive treatment to sweep the obstacles. It will be possible to make the cultural industry develop healthily and orderly.

\subsection{Establish the Fiscal Special Funds to Support the Cultural Industry}

Fiscal special funds is one of the most important, powerful and most widely used method to support the cultural industry.

\subsubsection{Use the Special Funds to Focus on Supporting the Upcoming Demise of the Cultural and Artistic Treasures}

The government can put in some support funds to help those important cultural enterprises, whose development situation is not optimistic. Use the substances to encourage and mobilize them to engage in cultural production with Shanghai characteristics, especially the musical groups, theater groups, etc. For some entertainment ornamental cultural institutions, they should not just indulge in performing the traditional arts programs repeatedly, but should be based on the changes in their existing characteristics and social life, and constantly incorporate new elements plus new content in the social development process emerged of Shanghai. They should keep pace with the times to make cultural products continue to meet modern tastes, so that it can attract the attention of the modern consumer. This can solve the problems of lacking substantive meaning of cultural products and convergence, enhance consumers' cultural identity and sense of belonging, and eventually save the upcoming demise of the cultural and artistic treasures.

\subsubsection{Use the Fiscal Funds Regularly to Organize Cultural Fair and Be Free Opening to the Consumers}

The governments can use the fiscal funds to hold the cultural fair regularly, choosing some excellent cultural products or work on exhibition in public, which can free open to consumers. It can make the creation and production units in direct contact with the consumers. This measure can not only help to stimulate consumers' desires of buying the outstanding cultural products, but also can help the production of cultural industry to absorb the valuable comments and suggestions from the consumers, so as to understand the advantages and disadvantages of their own cultural products or work in comparison with other existing industry. These companies should continuously overcome the inadequacies or weaknesses. They should focus on innovation, constantly improving the quality of cultural products, and jointly promoting the prosperity of cultural industry.

4.1.3 Pay Attention to the Role of Officer-industry-academy Cooperation, Use the Financial Resources to Cultivate the Cultural Creative Talents, Strive to Optimize the Allocation of Resources of the Company and Improve the Efficiency of Innovation Culture Industry

The government in Shanghai can play the role of the special funds on the cultural industry, provide some finance to support the companies who are potential. On the other hand, in order to get innovation of the development of Chinese cultural industry currently, talent is the key. Government can play the role of the finances, introduce various high -level cultural talents through a variety of ways to establish the long-term mechanism of retaining qualified personnel, and fully play the role of talents. However, the supply of talent cannot just rely on introduction, they should also need the help of major universities. Universities can offer some courses related to the cultural creation. At the same time, focusing on the cultivation of talents and the sense of innovation which can continuous supply the talent of cultural innovation for companies. Shanghai municipal government and corporations can jointly set up cultural and creative fund specialized in cultural innovation award for the college talent, and even offer bonuses for 
their study abroad, which will undoubtedly stimulate students' creative enthusiasm. Therefore, the innovation of cultural industry need officer-industry-academy cooperation.

4.1.4 Increase Financial Input in Terms of Strengthening the Advertising Efforts, and Guide Consumers to Establish a Correct Concept of Cultural Consumption

Shanghai municipal government should fully consider the important role of changing consumer attitudes on the development of cultural industry. There is an urgent need to give consumers a "brainwashing" to guide consumers to establish a correct concept of cultural consumption. Use the financial resources in collaboration with the advertising company, based on local culture of Shanghai, making cultural public service advertising. Then they can use a variety of media means such as television, radio, magazines and newspapers to guide and effect the consumers. Using this approach, not only can induce a profound impact on the consumer to establish a correct concept of cultural consumption, and enhance the sense of belonging to the local culture. Increasing the consumption of cultural products, in some degree, can be able to promote the development of cultural industry like advertising, media and so on. In the long term, it can promote the development and prosperity of cultural industries as a whole.

\subsection{Establish the Financial Subsidies}

Although we should pay attention to the nonprofit cultural institutions in which the position and positive role in the society, in the setting of socialist market economy, they should attach importance to the survival and development of enterprises profit organization. Therefore, to the use of financial subsidies, they should use the following ideas methods.

4.2.1 Financial Subsidies Can be Used to Focus on Supporting a Number of Small and Medium Enterprises or Institutions in Their Early Stages of Entrepreneurship

For some small and medium enterprises or institutions, they need considerable financial support in the early stage. In addition to their own funds and bank loans, the government can provide some funds for SMEs when they are in shortage of the capital. According to the development potential of the companies, they can divide funds into different levels rather than blindly invest. When the development of the SMEs are on the way and earn profit, then the government can receive financial compensation in the form of taxes. This part of the funds can be dedicated to the supplement of subsidy funds for SMEs.

\subsubsection{Financial Subsidies Can Be Supported for a Number of Nonprofit Cultural Enterprises and Institutions}

The government can use financial subsidies to keep the normal development of public cultural enterprises and institutions, to maintain the possibility of their survival. As we all know, nonprofit cultural enterprises has the feature of non-profit, so they do not participate in market competition, but they are an integral part. Their biggest problem is the lack of capital support, so they must rely on the help from the government for survival and development, relying on the power of public finances. When the use of special funds is not enough, the government can give them some financial subsidies to ensure the financial support they want to survive, which is helpful to continue to contribute to the unpaid social development, which is not due to funding problem while not surviving, making social development loss this important body.

\subsection{Reform the Tax System of Cultural Industry}

\subsubsection{The Government Can Adopt Differentiated Tax System}

The government can formulate a relatively fair tax policy for the cultural industry in this particular industry, and uses the different tax charged according to the different stages of business organizations as well as their profitability. In the cultural industry, small and medium cultural enterprises have the problem such as small scale, backward technology and weak credit. The SMEs are often at a disadvantage when competing with large-scale cultural enterprises. Therefore, differentiated tax policies should be adopted for this situation. They can take polarized tax system between unscrupulous companies and justifiable companies in the cultural industry. For some cultural production enterprise organizations who are in the initial stages, because of its profitability may not be very strong, the government can take encouraging policies, using the methods of combined taxation for several years, this will ensure companies to make more profit to expand production scale. For those in the period of development mature can be taxed as normal. In addition, for those who spread vulgar culture which will disturb the market order should not only be a bonus tax should also be imposed high fines. For those cultural companies who standardize their operations, the business tax and enterprise income tax can be combined to levy to avoid double taxation. For some export-oriented enterprises,can be removed tariffs but also appropriate to give some of the other tax benefits. 


\subsubsection{Adopt the Policy of the Directional Use of Taxation}

For some high-profit cultural industry such as karaoke and discos, the government can levy high consumption and entertainment tax. The taxes can be obtained to support the Shanghai portion of nonprofit cultural enterprises and the development of high culture. For some departments like arts and cultural performances, broadcasting and other cultural sectors, the profits and taxes they paid can be return to the competent authorities through the finance department, they can do some integrated management, focusing on supporting cultural career. In addition, inside the departments, various cultural funds or special funds may be established, in-house creative contest can be setted up to give appropriate incentives for those outstanding works which is designed to encourage the development of cultural and creative talents, and it is also helpful to stimulate the innovation and enthusiasm of creators.

\subsection{Set High Fines for the Behavior of Endangering Cultural Market}

The government should strengthen to combat the phenomenon of violations and impose high fines used for cultural innovation award. For the violation phenomena such as spreading vulgar culture and cultural piracy on the market, Shanghai municipal government should strengthen the surveillance efforts to the cultural market and improve the regulations of cultural market, and norm the cultural market order. The behavior of reporting the illegal acts of infringement can be given considerable bonus incentive, while the part of the illegal infringement must be taken quite high fines, which can be used to reward some positive cultural innovation and cultural enterprises or institutions engaged in high culture industry. It can stimulate their creativity to a certain extent. Standardizing the market order is beneficial to create a favorable market environment in favor of the development of high culture and the consumers' mental health, can help to improve the quality of cultural products on the whole. Fines are rewarded to cultural innovation and cultural products, is beneficial to culture industry to really move towards the goal of prosperity ultimately.

\subsection{Use the Forms of Tendering, Procurement and Others}

The government can use tendering, procurement and other forms to support cultural enterprises. The Third Plenary Session of the eighth has re-define the position of market in the allocation of resources, so the government must clearly recognize the crucial role of the market played in resource allocation, actively using tendering, procurement and other market-based instruments to promote the development of cultural enterprises or institutions. The ways like tendering and procurement can maximize to optimize the allocation of resources and ensure the entire quality of cultural products. In this way, it can not only better play the role of the market itself, reflect fair competition and maintain the vitality of an orderly market, but also can promote the units of cultural production and creation to healthily compete which can ensure the quality of cultural products. In addition, it can stimulate innovation and vitality to maintain to steadily develop. As the saying goes"kill two birds with one stone". Under the setting of socialist market economy, Shanghai municipal government should seriously and clearly fulfills his own duties, and make full use of the two financial means of tendering and procurement to support the development of cultural industry.

\subsection{Use the Methods of Financial Transfer Payment}

The government can use the methods of financial transfer payment to promote the development and prosperity of cultural industry in Shanghai. Using this indirect way which is more modest means, can play the sound development of cultural industry to achieve the purpose. For example, the government can set some innovation competition about cultural industry for all types of the small or medium companies and individuals inside the industry. The award-winning companies or individuals can gain a huge bonus, so this will encourage businesses and individuals to innovate. At the same time, the award-winning enterprise regardless size can also get a certain reputation, free to do publicity for the enterprise, which is particularly beneficial to the development and growth of SMEs. In addition, the government can use the means of tax returns to promote the development of cultural industry. To some high quality cultural products of exports, except the basic customs duties system, you can also use the way of tax returns to help to support fund for its development. The exports of these cultural products gaining a foothold in overseas markets, not only could open the way for China's exports of other cultural products, but also can enhance the sense of belonging to the people of local culture products of Shanghai, and stimulate consumers' demand for them. In the end, from outside to inside, from the local to the whole ground step by step, they can comprehensively promote the development of cultural industry.

\section{Conclusion}

The development and the prosperity of Shanghai's cultural industry can not be done overnight. But as the focus of the 
work during the transition phase, the development of cultural industry must be placed in a very important position. At this moment, only on the basis of the function of market, combined with public finance, comprehensively using all kinds of ways about public finance can promote the development of cultural industry. When the free development of the cultural market is in the condition of disruption, the government should emphasize on the role of public finances, steadily enhance people's cultural belonging, reduce the spillover of cultural products, enrich the substance of cultural products, prevent the spread of vulgar culture and cultural infringement, save face extinction cultural and artistic treasures, and help small and medium cultural enterprises. The government should face the problems in all aspects in the development of cultural industry and overcome various obstacles in this process. In order to achieve a smooth transition and ultimately successfully achieve the grand goal of Shanghai's economic transformation, the government should promote the vigorous development of cultural industry as a whole.

\section{References}

Cai Rongsheng, \& Wang Yong. (2009). Policy researches of the development of cultural and creative industry at home and abroad. China soft science, 8, 77-84.

Chen Guoquan. (2012). Some reflections about Shanghai cultural industry development. Shanghai commercial, 9 , $10-11$.

Du Xiaowei. (2013). Promote the development of cultural industry fiscal policy -theoretical basis and Policy Design. Friends of accounting, 19, 87-90.

Han Hui, \& Wujiang. (2009). Fiscal policies to promote cultural industry development research. Modern economic information, 19, 62.

Kuang Daoqiu. (2012). Construction of public financial support for culture: motives, mechanisms and paths. Vision, 6, 36-40.

Li Benqian, Chen Xiaoyun, \& Chen Dejin. (2010). Shanghai cultural industry development and cultural system to promote collaborative research. Scientific development, 6, 92-102.

Liu Xuehua, Chen Hairong, \& ChenGong. (2013). Shanghai to promote the integration of culture and technology depth study. Scientific development, 9, 49-59.

Wu Xueli, \& Li Xiujin. (2010). Local fiscal policy to promote cultural industry development research. Economic horizon, 2, 81-83 (007-7685(2010)02-0081-03).

Ye Juhua. (2013). The comparison and reference of international cultural industry fiscal policy. Chinese collective economy, 19, 93-94.

Zhang Hong. (2012). Revelation about the development of cultural industry in Shanghai. Youth correspondent, 9 , 38-39.

Zhang zhao'an. (2010). Culture and cultural industry development in Shanghai. Shanghai business, 12, 39-40.

Zhu Ruibo, \& Liu Yun. (2011). General characteristics, institutional barriers and mechanism innovation of the development of strategic emerging industries in China. Social sciences, 5, 65-72. 